\title{
Levantamento dos gastos em biodiversidade no estado de Pernambuco - Brasil
}

Biodiversity expenditure review in the state of Pernambuco - Brazil

Análisis de los gastos en biodiversidad en el estado de Pernambuco - Brasil

\author{
Wilson Barbosa da Silva Júnior \\ wilsonjunior0696@gmail.com \\ Instituto Federal de Educação, Ciência e Tecnologia de Pernambuco - Brasil \\ https://orcid.org/0000-0002-2111-1506
}

Beatriz Oliveira Gomes Florencio

beatriz15301@gmail.com

Instituto Federal de Educação, Ciência e Tecnologia de Pernambuco - Brasil https://orcid.org/0000-0003-1354-2864

Luizmar Vidal de Negreiros

luizmaraha@gmail.com

Instituto Federal de Educação, Ciência e Tecnologia de Pernambuco - Brasil https://orcid.org/0000-0001-6219-2712

Carlos Eduardo Menezes da Silva

carlosmenezes@ @ecife.ifpe.edu.br Instituto Federal de Educação, Ciência e Tecnologia de Pernambuco - Brasil https://orcid.org/0000-0003-1156-156X

\section{RESUMO}

A Iniciativa Finanças pela Biodiversidade (BIOFIN) do Programa das Nações Unidas para o Desenvolvimento (PNUD) auxilia os governos no aprimoramento das políticas de conservação da biodiversidade. Aplicou-se no presente trabalho a abordagem BIOFIN na avaliação dos gastos com biodiversidade no estado de Pernambuco, mais especificamente, a etapa de revisão de gastos em biodiversidade - biodiversity expenditure review (BER). Analisou-se os gastos públicos estaduais entre 2008 a 2021, selecionando os programas e ações relacionados direta ou indiretamente com a biodiversidade. Os gastos totais em biodiversidade em relação ao PIB, representaram em média $0,168 \%$, e aos gastos totais do Estado, em média 1,024\%. Os gastos diretos com a biodiversidade, em relação ao PIB, representaram em média $0,007 \%$, e aos os gastos totais do estado, em média $0,040 \%$. Dos gastos totais com biodiversidade, apenas $4,1 \%$ são gastos diretos. Constatamos assim um quadro de subfinanciamento da biodiversidade em Pernambuco. Sendo assim, mecanismos inovadores de financiamento precisam ser estabelecidos para fechar essa grande lacuna.

Palavras-chave: BIOFIN. Economia ambiental. Gastos públicos.

\begin{abstract}
The Finance for Biodiversity Initiative (BIOFIN) of the United Nations Development Program (UNDP) assists governments in improving biodiversity conservation policies. In this work, the BIOFIN approach was applied in the assessment of expenditure on biodiversity in the State of Pernambuco, more specifically, the stage of review of expenditure on biodiversity (BER). State public expenditures between 2008 and 2021 were analyzed, selecting programs and actions directly or indirectly related to biodiversity. Total expenditure on biodiversity about GDP represented an average of $0.168 \%$, and the State's total expenditure, an average of $1.024 \%$. In relation to GDP, direct expenditures on biodiversity represented an average of $0.007 \%$, and the state's total expenditures, on average, $0.040 \%$. Of the total expenditure on biodiversity, only $4.1 \%$ is direct expenditure. Thus, we see a framework of underfunding for biodiversity in Pernambuco. Therefore, innovative financing mechanisms need to be established to close this enormous gap.
\end{abstract}

Keywords: BIOFIN. Environmental economics. Public spending.

\section{RESUMEN}

La Iniciativa de Financiamiento de la Biodiversidad (BIOFIN) del Programa de las Naciones Unidas para el Desarrollo (PNUD) ayuda a los gobiernos a mejorar las políticas de conservación de la biodiversidad. En el presente articulo, se aplicó el enfoque BIOFIN en la evaluación de los gastos en biodiversidad en el estado de Pernambuco, más específicamente, la etapa de análises de gastos en biodiversidade. Se analizó el gasto público estatal entre 2008 y 2021 , seleccionando programas y acciones relacionadas directa o indirectamente con la biodiversidad. Los gastos totales en 
biodiversidad en relación al PIB, representaron un promedio de $0,168 \%$, y los gastos totales del estado, un promedio de $1,024 \%$. Los gastos directos en biodiversidad, en relación al PIB, representaron en promedio 0,007\%, y los gastos totales del Estado, en promedio, 0,040\%. Del total de gastos en biodiversidad, solo el 4,1\% son gastos directos. Así, podemos ver un cuadro de desfinanciamiento de la biodiversidad en Pernambuco. Por lo tanto, es necesario establecer mecanismos de financiación innovadores para cerrar esta gran necessidad.

Palabras clave: BIOFIN. Economía ambiental. Gasto público.

\section{INTRODUÇÃO}

Em um mundo com uma crescente ascensão populacional, a perda da biodiversidade está entre os principais riscos globais para a sociedade. As florestas naturais diminuíram 6,5 milhões de hectares por ano entre 2010 e 2015 e as áreas úmidas naturais diminuíram 35\% entre 1970 e 2015 (OECD, 2019). O Living Planet Index, que mede mais de 10.000 populações de mamíferos, aves, répteis, anfíbios e peixes, expôs que dessas populações, foram extintas cerca de $52 \%$ desde 1970 (MCLELLAN et al., 2014). Essas mudanças são causadas por mal uso da terra, exploração excessiva de recursos naturais, poluição, espécies exóticas invasoras e mudanças climáticas (OECD, 2019).

A área total de floresta primária úmida em Pernambuco diminuiu $96 \%$ nesse período (GLOBAL FOREST WATCH, 2019). Em Pernambuco, o ecossistema Mata Atlântica é considerado internacionalmente como área prioritária para as ações de conservação, pela sua grande riqueza natural e elevada biodiversidade, e por conta disso, é reconhecido como um hotspot da biodiversidade (CARDOSO DA SILVA; MARINS; TABARELLI, 2002). A caatinga, bioma endêmico do Brasil, e que ocupa grande parte de Pernambuco, contém uma grande biodiversidade e abriga por exemplo, uma fauna estimada de 148 espécies de mamíferos (NASCIMENTO; FERREIRA; MOURA, 2013). Diante do quadro exposto, a importância de maiores investimentos para a conservação da biodiversidade torna-se primordial nesse contexto.

E dentre os esforços para reverter esse cenário de perda progressiva de biodiversidade os governos buscaram estabelecer diversos acordos (UNDP, 2018a). Um dos principais acordos estabelecidos é a Convenção da Diversidade Biológica (CDB). Dentre os muitos pontos previstos na CDB destaca-se a discussão sobre o que hoje se conhece como financiamento para a biodiversidade, (ROJAS, 2016). Como ponto de partida no financiamento para a biodiversidade temos a revisão ou identificação dos gastos realizados para esse fim. A identificação dos gastos ambientais realizados por um governo se constitui em ferramenta importante para avaliar a relevância que o tema ocupa nas agendas públicas e privadas, uma vez que se constituem em um dos indicadores das prioridades e compromissos assumidos na busca do desenvolvimento sustentável (CEPAL, 2015). No setor público, o montante gasto nas políticas ambientais ajuda a indicar a atuação dos governos no tema ambiental e a posição que este ocupa no conjunto das políticas públicas, bem como na disputa entre diversos interesses (MOURA et al., 2017).

A avaliação dos gastos públicos ambientais é deveras importante, pois fornece informações adicionais para a tomada de decisão, para pesquisas científicas e para a gestão ambiental (FALCO, 2017). De acordo com Secchi (2010), como as necessidades ambientais mais cruciais devem ser entendidas como um problema público, cabendo ao Estado assumir o papel central no processo de elaboração das políticas públicas, o setor público consiste no maior financiador das ações ambientais. Portanto, a avaliação de alocação de recursos que tenha como finalidade a gestão ambiental é fundamental, embora isso seja recente nos governos (DANTAS et al., 2014).

A fim de integrar a biodiversidade e seus serviços ecossistêmicos na tomada de decisões, os criadores de políticas públicas precisam regularmente ter um fornecimento atualizado e consistente de informações sobre a biodiversidade e os benefícios que ela oferece. Além disso, a avaliação dos 
gastos ambientais pode respaldar análises de todos os órgãos estatais para um planejamento econômico central mais ecológico. (KING et al., 2021).

Apesar da importância da avaliação de gastos com a biodiversidade como ferramenta de gestão, ainda há pouquíssima informação em nível de governos nacionais, e ainda menos no que diz respeito a governo sub-nacionais. Diante disso, no ano de 2012, nasceu a Iniciativa de Financiamento da Biodiversidade (BIOFIN), uma parceria global gerenciada pelo Programa das Nações Unidas para o Desenvolvimento (PNUD), cujo objetivo é o de apoiar os tomadores de decisão na avaliação da necessidade de financiamento, além da concentração dos fundos devidos para almejar êxito em políticas e planos nacionais relacionados com biodiversidade. Em todo o mundo até o fim de 2019, 36 países já tinham implementado a Iniciativa.

Dessa forma, esse trabalho se justifica na tentativa de contribuir com o esforço crescente de adoção da metodologia BIOFIN nos orçamentos governamentais. No contexto atual, as atuais dificuldades orçamentárias restringem as possibilidades de ampliação de recursos, colocando um importante desafio na execução dos programas e ações estatais. Por essa razão, analisar onde e como é aplicado cada recurso que visa uma maior preservação ambiental torna-se pertinente e relevante em face do momento atual de destruição ambiental em que vivemos.

A face do exposto, o objetivo principal deste trabalho foi realizar um levantamento dos gastos públicos com biodiversidade do Governo do estado de Pernambuco, compreendendo os seguintes objetivos específicos: identificar os principais documentos legais de planejamento e organização dos orçamentos do estado de Pernambuco; classificar os dados de gastos públicos, ou seja, programas e ações do estado de acordo com as classes e subclasses BIOFIN conforme metodologia da UNDP (2018a); relacionar os gastos públicos com biodiversidade com o panorama macroeconômico do estado e traçar cenários futuros de gastos públicos de acordo com as classes e subclasses BIOFIN.

Essa pesquisa é composta por 5 seções: esta atual, a introdução, fornece informações gerais acerca deste trabalho; a segunda apresenta o embasamento da pesquisa, apresentando alguns conceitos importantes a serem entendidos sobre a metodologia BIOFIN e o Sistema Orçamentário Brasileiro; a terceira trata sobre os procedimentos metodológicos adotados na pesquisa; a quarta apresenta os resultados e discussões do trabalho; e a quinta seção traz as considerações finais e conclusões da pesquisa.

\section{FUNDAMENTAÇÃO TEÓRICA}

\subsection{Iniciativa BIOFIN}

A iniciativa BIOFIN abrange a realização de quatro estudos, que resultam na construção de uma estratégia de mobilização de recursos financeiros para a biodiversidade: Revisão do Marco Institucional, Político e Financeiro da Biodiversidade (PIR); Levantamento de gastos em biodiversidade (BER); Avaliação de fluxos de financiamento e necessidades na gestão da biodiversidade (FNA); e o Plano de Financiamento da Biodiversidade (BFP).

Conforme expõe a UNDP (2018a), maior parte das ações que o BIOFIN reconhece e prioriza são colocadas no âmbito financeiro. Para isso, o Levantamento de Gastos em Biodiversidade (Biodiversity Expenditure Review - BER) mensura a parcela de capital gasto por algum país de maneira deliberada em efeitos benéficos para a biodiversidade.

Ainda segundo a UNDP (2018a), o BER figura como uma forma mais evoluída de revisão dos gastos estatais, tornando mais restrita a análise e quantificando o montante gasto de forma 
intencional em resultados positivos para a biodiversidade. Mediante isso, o presente trabalho adotou o BER como o método a ser adotado para analisar os gastos.

Sabemos que o diagnóstico do status quo dos gastos com conservação da biodiversidade é bastante importante na iniciativa BIOFIN. Outrossim, o BIOFIN tem como objetivo principal avaliar de forma comparativa o empenho dos países em conservar a biodiversidade. A fim de que essa comparação seja feita, os recursos gastos pelos países são avaliados de acordo com nove classes e 63 subclasses (ANEXO 1). Qualquer uma dessas subclasses, apresenta um grau de importância que é determinada pelo grau de vínculo com a conservação da biodiversidade. Esse grau de importância determina a porcentagem de vínculo com a biodiversidade. O intervalo de níveis de atribuição pode variar de 0 a 100\% (UNDP, 2018a). Qualquer classe que contenha o grau de ponderação $100 \%$ se caracteriza como gasto direto com biodiversidade e as restantes, gasto indireto com a biodiversidade.

O Gasto direto em biodiversidade é qualquer despesa cujo propósito é ter um impacto positivo, reduzir ou eliminar as pressões sobre a biodiversidade. Esses gastos incluem despesas que têm a biodiversidade como seu objetivo principal. Já os gastos indiretos com biodiversidade são aqueles que têm a biodiversidade como finalidade secundária ou conjunta (UNDP, 2018a).

Por essa razão, mesmo que os gastos filtrados sejam considerados gastos com biodiversidade, se não tiverem uma relação direta com a Iniciativa BIOFIN, passam a ter uma menor influência ou nenhuma se aplicado o fator BIOFIN na análise.

\subsection{Sistema de orçamento e planejamento brasileiro}

A Constituição Federal nos arts. 165 a 169 fixou uma organização geral para o Sistema Orçamentário Brasileiro baseada em uma hierarquia de três leis ordinárias: a Lei do Plano Plurianual (PPA), a Lei de Diretrizes Orçamentárias (LDO) e a Lei Orçamentária Anual (LOA) (MENDES, 2009).

Segundo Mendes (2009), o PPA é o mais extenso. Este dura quatro anos. Sua função é dar guia, objetivos e metas para os investimentos públicos e para as despesas que perduram por dois exercícios fiscais ou mais. Por conta disso, configura-se em um instrumento de planejamento a médio prazo.

$\mathrm{Na}$ administração pública, o orçamento é um documento aprovado por lei, contendo, basicamente as receitas previstas e as despesas que se pode realizar em um período de tempo (GARSON, 2018).

Para a aprovação do orçamento, ocorre a discussão pelo legislativo do projeto de lei enviado pelo executivo, a apresentação de sugestões dos parlamentares e a votação do final do texto acordado. Sendo aprovado, o texto retorna ao Executivo, que por sua vez, é incumbido da execução do orçamento aprovado pela casa legislativa.

Segundo Garson (2018), ao configurar o processo decisório em cada um desses estágios, as instituições orçamentárias criam incentivos e restrições com que se defrontam os diferentes atores do setor público no Legislativo e no Executivo e os grupos de interesse da sociedade.

A metodologia de elaboração de programas do PPA facilita a identificação dos problemas e dos segmentos sociais que devem ser alvo da intervenção governamental, estabelecendo as ações a serem implementadas e os resultados a serem alcançados (MPOG, 2007). Segundo Moura et al. (2017), os programas retratam a agenda do governo, organizada por recortes de políticas públicas. 


\section{PROCEDIMENTOS METODOLÓGICOS}

\subsection{Análise e classificação dos dados}

De acordo com a UNDP (2018a), o BER deve procurar atribuir as despesas da maneira mais precisa possível, usando critérios e processos de atribuição bem definidos e transparentes. Existem duas abordagens em potencial para a atribuição de despesas: a abordagem de programa, com foco nas despesas detalhadas dos programas e a abordagem de agência, com foco nas organizações que fazem as despesas. A abordagem de programa é considerada a melhor prática, pois garante que os dados do orçamento e das despesas sejam associados a programas, atividades, metas e indicadores específicos.

A coleta e a análise dos dados foram baseadas na metodologia desenvolvida por Mendes et al. (2017), que avalia os gastos públicos ambientais. Segundo Mendes et al. (2017), na primeira etapa as informações devem ser obtidas somente em repositórios/fontes públicas de dados. Na segunda etapa procede-se a análise dos Planos Plurianuais (PPA), na terceira etapa devem ser selecionados todos os programas, projetos e atividades relacionados ao propósito a ser analisado.

Assim sendo, foram obtidos através do Portal da Transparência do Governo do estado de Pernambuco as bases de dados com todos os programas e ações do Governo de Pernambuco do ano de 2008 até o ano de 2021. Após a obtenção dos dados, foram realizadas as análises de três PPAs: 2008-2011, 2012-2015, 2016-2019 e os dois primeiros exercícios fiscais do PPA 2020-2023. Para tanto, fez-se o uso do software Open Refine. Software esse que possibilita o tratamento e a manipulação de dados, especialmente quando estes estão desorganizados ou apresentam inconsistências (SCOGNAMIGLIO; BRIGO, 2016). Por intermédio dessa ferramenta, foi possível filtrar os programas e ações realizados pelo Governo do estado de Pernambuco, que tinham relação com a proteção do meio ambiente e da biodiversidade. Só depois passou-se a classificar cada programa e ação por classe e subclasse BIOFIN.

\subsection{Elaboração dos cenários futuros}

Nesta fase da análise, o BER busca esboçar os gastos futuros com biodiversidade com base nas tendências de gastos em anos anteriores. Segundo expressa a UNDP (2018a), as projeções futuras devem abranger um período futuro de aproximadamente 5 a 10 anos. Os países que historicamente demonstram muita variação nas taxas de câmbio e inflação devem adotar uma abordagem de média móvel ponderada (WMA) de três ou cinco anos para reduzir o erro de previsão em previsões futuras devido a variações de curto prazo incomuns ou temporárias nesses fatores.

Entretanto, com o surgimento da Emenda Constitucional 95/2016 que limita por 20 anos os gastos públicos, tende a reforçar o papel marginal da política ambiental no país nas próximas duas décadas, pois não apenas fixa o congelamento do gasto primário em um momento em que este já apresentava trajetória descendente mas também deve resultar em cortes mais agudos nas ações ambientais, justamente por ser percebida como marginal frente a outras políticas, especialmente aquelas que apresentam piso de gasto, tais como saúde e educação (ROSSI; DWECK; OLIVEIRA, 2018).

Foi utilizado nesse trabalho para mensurar os cenários de gastos futuros, a média móvel de 3 anos anteriores de cada exercício fiscal, chegando até o ano de 2030 e na vigência da EC 95/2016, o cenário de congelamento de gastos por classe BIOFIN. 


\section{RESULTADOS E DISCUSSÃO}

\subsection{Documentos legais de planejamento e organização dos orçamentos do estado de Pernambuco}

No que tange aos principais documentos legais de planejamento e organização dos orçamentos do estado de Pernambuco, no quadro 1 estão apresentadas as 10 leis identificadas e que são referentes a questões ambientais. Essas leis foram utilizadas para subsidiar o filtro das ações do Governo do estado de Pernambuco com biodiversidade.

Quadro 1 - Leis utilizadas na filtragem das ações estaduais em prol da biodiversidade.

\begin{tabular}{|c|c|c|}
\hline Lei & Data & Descrição da Lei \\
\hline 11.206 & 31 de março de 1995 & Dispõe sobre a Política Florestal do estado de Pernambuco. \\
\hline 12.984 & 30 de dezembro de 2005 & Dispõe sobre a Política Estadual de Recursos Hídricos. \\
\hline 13.787 & 08 de junho de 2009 & $\begin{array}{l}\text { Institui o Sistema Estadual de Unidades de Conservação da Natureza } \\
\text { (SEUC). }\end{array}$ \\
\hline 14.090 & 17 de junho de 2010 & $\begin{array}{l}\text { Institui a Política Estadual de Enfrentamento às Mudanças Climáticas de } \\
\text { Pernambuco. }\end{array}$ \\
\hline 14.091 & 17 de junho de 2010 & $\begin{array}{l}\text { Institui a Política Estadual de Combate à Desertificação e Mitigação dos } \\
\text { Efeitos da Seca. }\end{array}$ \\
\hline 14.236 & 13 de dezembro de 2010 & Dispõe sobre a Política Estadual de Resíduos Sólidos. \\
\hline 14.258 & 23 de dezembro de 2010 & Institui a Política Estadual de Gerenciamento Costeiro. \\
\hline 15.223 & 24 de dezembro de 2013 & $\begin{array}{l}\text { Institui a Política Estadual de Assistência Técnica e Extensão Rural para } \\
\text { Agricultura Familiar de Pernambuco - PEATER-PE e o Programa Estadual } \\
\text { de Assistência Técnica e Extensão Rural da Agricultura Familiar - } \\
\text { PROATER-PE. }\end{array}$ \\
\hline 15.809 & 17 de maio de 2016 & Institui a Política Estadual de Pagamento por Serviços Ambientais. \\
\hline 16.688 & 06 de novembro de 2019 & Institui a Política de Educação Ambiental de Pernambuco. \\
\hline
\end{tabular}

Fonte: Os autores, 2022.

Apesar do grande arcabouço jurídico existente no estado de Pernambuco, observamos que nas décadas de 90 e 2000 não havia uma quantidade satisfatória de leis que correspondiam de forma direta ou indireta a proteção ambiental, embora as mesmas fossem uma evolução na política 
ambiental do estado de Pernambuco. A consequência disso são poucas ações na área ambiental realizadas pelo Governo do Estado de Pernambuco no primeiro PPA analisado (2008-2011).

Com o surgimento nas décadas seguintes de novas legislações nesse sentido, a quantidade de ações ambientais do Governo Estadual cresceu de forma veemente nos PPAs posteriores. A importância do aumento da presença de legislações nesse sentido só reforça o que expõe Tridapalli et al. (2012): o Estado desempenha papel fundamental e insubstituível no processo de regulação ambiental como representante do interesse público e garantidor de direitos ambientais.

\subsection{Gastos com biodiversidade}

A observação dos gastos do estado de Pernambuco associados com a gestão da biodiversidade, revelou um total de 85 Programas e 231 Ações (Ver material complementar). A análise desses programas e ações demonstrou que houve um crescimento de gastos públicos nessa área de 2008 a 2014, caindo em 2015. Os gastos em 2016 voltaram a crescer até 2018, ano onde teve a maior quantidade de recurso executado. Entretanto, em 2019, os valores voltaram a cair a patamares semelhantes a cinco anos anteriores. Após dois anos em queda, no ano de 2021 houve um crescimento grande dos gastos com biodiversidade chegando próximo ao que era executado em 2018, que foi o melhor ano de recurso aplicado.

Entretanto, é relevante a diferença entre os gastos diretos e indiretos com biodiversidade. Os gastos indiretos com biodiversidade são majoritariamente superiores aos gastos diretos conforme expõe a Figura 1. As despesas diretas com biodiversidade nos anos de 2008 a 2021 tiveram uma variação mínima de R \$ 2,1 milhões em 2009 e máxima de R \$ 56,3 milhões em 2017. Na contramão disso, as despesas indiretas variaram de no mínimo R \$4,7 milhões em 2010 a no máximo em R\$ 565,5 milhões em 2018. Isso indica que se considerarmos os gastos totais com biodiversidade, notamos que a média anual do gasto direto é na ordem dos $\mathrm{R} \$ 11,2$ milhões e a média dos gastos indiretos fica em torno dos $\mathrm{R} \$ 264,1$ milhões. A partir disso, é possível dizer que dos gastos com biodiversidade do estado de Pernambuco, apenas uma média de 4,1\% são realmente dirigidos para ações cujo objetivo é o impacto total na conservação, preservação e uso sustentável do capital natural.

Figura 1 - Gastos diretos e Indiretos em biodiversidade no orçamento do estado de Pernambuco entre 2008 e 2021.

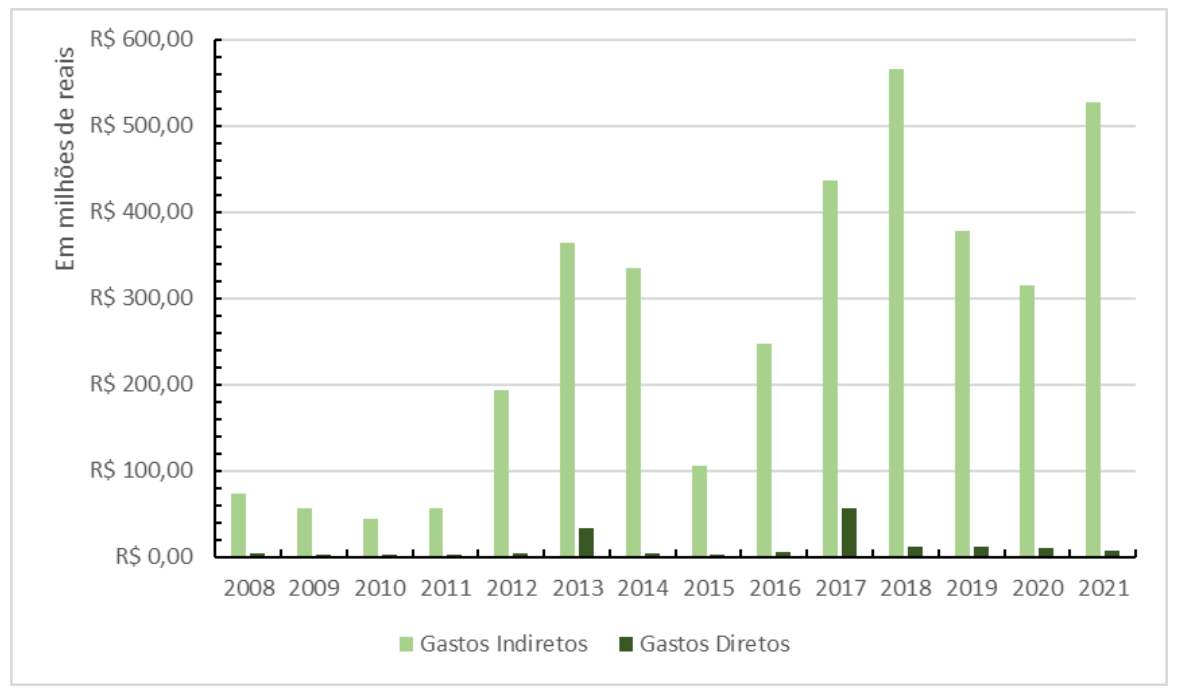

Fonte: Elaborado pelo autor com base nos dados do Portal da Transparência do estado de Pernambuco, com valores de gastos pagos deflacionados pelo IPCA para 2021. 
A partir da análise dos dados obtidos, é possível afirmar que, embora tenhamos tido um leve crescimento nos anos de 2013 e 2017 da execução dos gastos com o objetivo de gerir a biodiversidade no estado de Pernambuco, esses gastos não se mantém de maneira uniforme. Podemos encarar isso de forma preocupante, visto que o gasto público apresenta um papel crucial na política ambiental, uma vez que seus principais instrumentos, tais como físcalização do cumprimento de padrões e normas ambientais, controle do desmatamento ilegal e manutenção de Unidades de Conservação (UCs), dependem criticamente da disponibilidade de verbas públicas (ROSSI; DWECK; OLIVEIRA, 2018).

A grande diferença entre os gastos diretos e os gastos indiretos pode ser observada também em outros trabalhos, cujo objetivo foi o levantamento de gastos públicos ambientais. Ribeiro (2011) já tinha verificado em sua análise, que os gastos dos estados com serviços urbanos e saneamento básico se sobressaíram em relação as despesas com preservação ambiental. Áreas como a gestão ambiental propriamente dita não receberam atenção significativa no planejamento governamental. Uma possível explicação é a ineficiência das políticas dos governos estaduais para manutenção e controle dos recursos naturais ainda existentes no País (RIBEIRO, 2011).

O cenário do financiamento da biodiversidade no estado de Pernambuco parece refletir a realidade global na qual a mobilização de recursos não é suficiente para atingir as metas de conservação estabelecidas pela CBD (DZIBA et al., 2019). E mesmo sendo uma questão global, alguns países são mais subfinanciados do que outros representando prioridades urgentes (WALDRON et al., 2017). É o caso do Brasil, onde a escassez de recursos financeiros tem sido endêmica no nível federal, com pequenas variações ao longo dos anos, entre 1992 e 2017, os gastos ambientais variaram entre $0,2 \%$ e $0,5 \%$ do gasto federal total (GRAMKOW, 2018; TRIDAPALLI et al., 2012; YOUNG; RONCISVALLE, 2002).

A situação do estado de Pernambuco parece por um lado despertar um alerta pelo aparente subfinanciamento da conservação. Por outro lado, há pouco ou nenhuma informação sobre o gasto com conservação em nível de país e ainda mais em nível subnacional. Consequentemente também existem poucos dados em nível global, cujas estimativas chegam a um montante de U\$ 49 bilhões anuais (OECD, 2019; SEIDL et al., 2020). Desta forma também há dificuldades de se saber qual o percentual das necessidades de recursos para conservação atuais. As estimativas atuais sobre isso variam de US\$ 58 a US\$ 524 bilhões por ano (OECD, 2020; PARKER et al., 2012).

Em vista disso, o cenário de restrição fiscal dos governos introduz desafios adicionais para o poder público atuar na proteção ambiental. Faz-se necessário buscar alternativas de financiamento para evitar os piores impactos sobre a política ambiental (ROSSI; DWECK; OLIVEIRA, 2018). Assim, incentivos econômicos, como cobranças ambientais ou a remoção de incentivos adversos, devem ser utilizados sempre que possível, além de subsídios para o uso sustentável, sempre que necessário. Isso garantirá que os custos de proteção dos valores da biodiversidade sejam reduzidos (MOUNTFORD; KEPPLER, 1999). A falta de capital dos governos para investimento na área ambiental é um dos maiores empecilhos para almejar êxito nos acordos ambientais de proteção e conservação do meio ambiente (WALDRON et al., 2013). Embora os investimentos com impacto em larga escala na conservação sejam mais efetivos no âmbito nacional, as estratégias estaduais de conservação podem ser um tanto significativas (ARIAS et al., 2016).

No que diz respeito aos gastos orçamentários do estado de Pernambuco com Biodiversidade, existe uma demasiada discrepância entre os gastos autorizados e os pagos. No período 2008-2021, os pagos corresponderam em média a $58,1 \%$ dos autorizados. Essa taxa percentual alternou ao longo do período analisado. A figura 2 mostra que os anos onde ocorreram os dois maiores percentuais de valores pagos em relação aos autorizados foram os anos de 2017 e 2018 com 90,97\% e $86.09 \%$ respectivamente. Do outro lado, os anos com os dois menores percentuais foram 2011 com $23,60 \%$ e 2012 com $30,53 \%$. 
Figura 2 - Comparação entre os gastos totais em biodiversidade autorizados e pagos no orçamento do estado de Pernambuco entre os anos de 2008 e 2021.

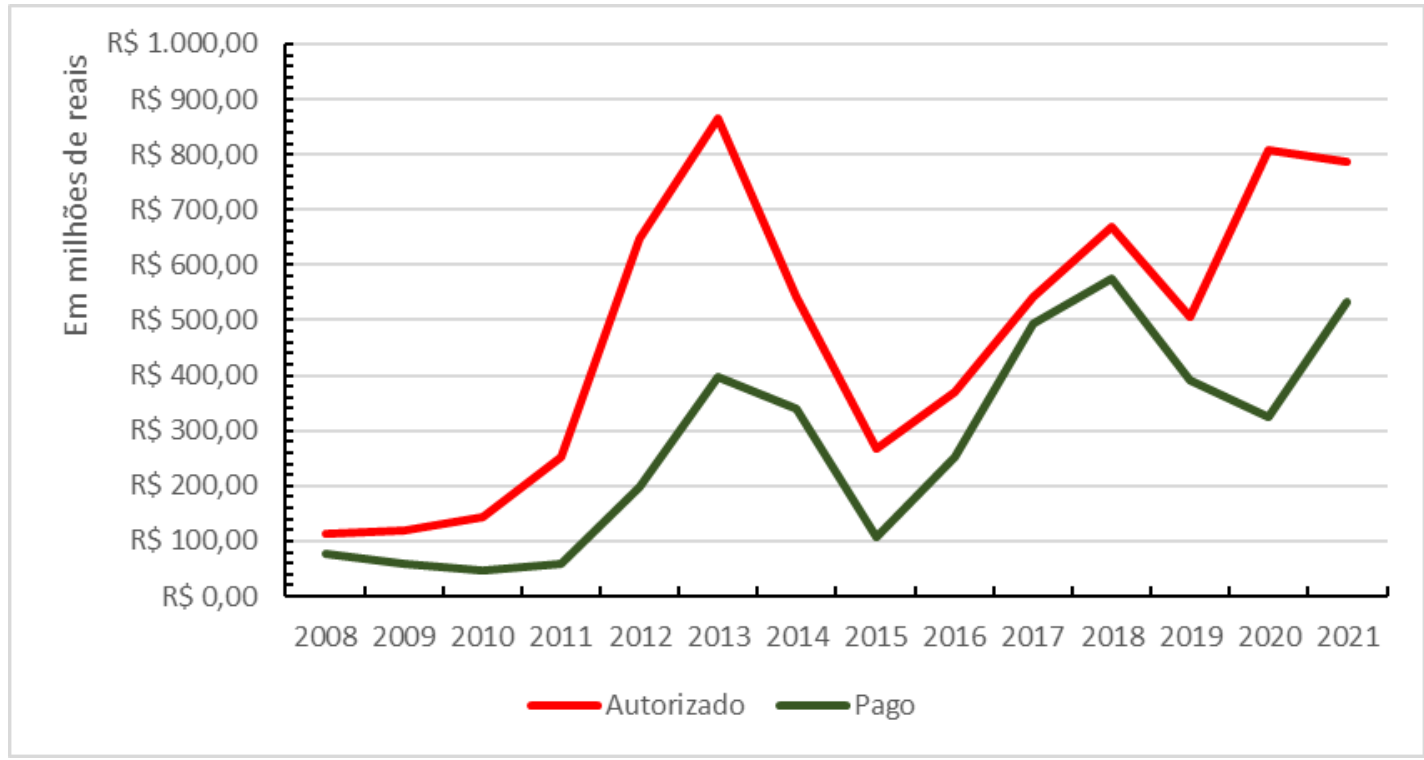

Fonte: Elaborado pelo autor com base nos dados do Portal da Transparência, com valores pagos deflacionados pelo IPCA para o ano de 2021.

É relevante afirmar: a elaboração do orçamento percorre estágios e a efetivação dos gastos, deve se nortear pelas autorizações do orçamento. O comportamento financeiro da instituição pública é resultado da execução de determinada programação, a qual se reveste da forma orçamentária em seu respectivo instrumento (GIACOMONI, 2010 apud COUTO; NETO; RESENDE, 2018). Diante do exposto, podemos dizer que é preciso que os estágios da elaboração do orçamento sejam verificados. Pois segundo Garson (2018), mesmo que os recursos estejam autorizados na LOA, estes podem não ser executados, desencadeando assim prejuízos na efetivação da ação proposta. Portanto, essa diferença entre os recursos autorizados e os realmente pagos, são capazes de determinar a habilidade do Governo em gestão da Biodiversidade.

No período examinado exposto na tabela 1, o ano de 2008, teve o gasto total com biodiversidade na ordem de $\mathrm{R} \$ 77.029 .173,44$ e no período final da análise, em 2021 , R \$ 533.847.856,73. Isso significa um acréscimo de 593.04\% do primeiro ao último ano do recorte temporal. Porém ao comparar os gastos totais em biodiversidade com o PIB do Estado, no período analisado, os gastos totais em biodiversidade representaram em média 0,168\% do PIB do estado de Pernambuco, atingindo um máximo de $0,316 \%$ no ano de 2018 e um mínimo de 0,049\% no ano de 2010. Os gastos totais em biodiversidade representaram em média $1,024 \%$ dos gastos totais do Estado, atingindo um pico de $1,985 \%$ no ano de 2013 e um mínimo de $0,351 \%$ no ano de 2010. Quando se consideram apenas os gastos diretos com o PIB, estes representaram em média 0,007\% com um máximo de $0,031 \%$ no ano de 2017 e um mínimo de $0,001 \%$ no ano de 2015 . Se considerarmos apenas os gastos diretos com os gastos totais do estado, estes representaram em média 0,040\%, atingindo um máximo de 0,167\% em 2013 e um mínimo de 0,013\% no ano de 2009 dos gastos totais do Governo de Pernambuco. Esses dados corroboram com a afirmação de que o peso dos gastos com biodiversidade no orçamento do estado de Pernambuco é muito pequeno, apesar de ainda termos uma grande quantidade de recursos naturais para preservar e conservar. 
Tabela 1 - Relação entre PIB, gastos totais estaduais, gastos totais em biodiversidade e gastos indiretos e diretos em biodiversidade no orçamento estadual entre os anos 2008-2021.

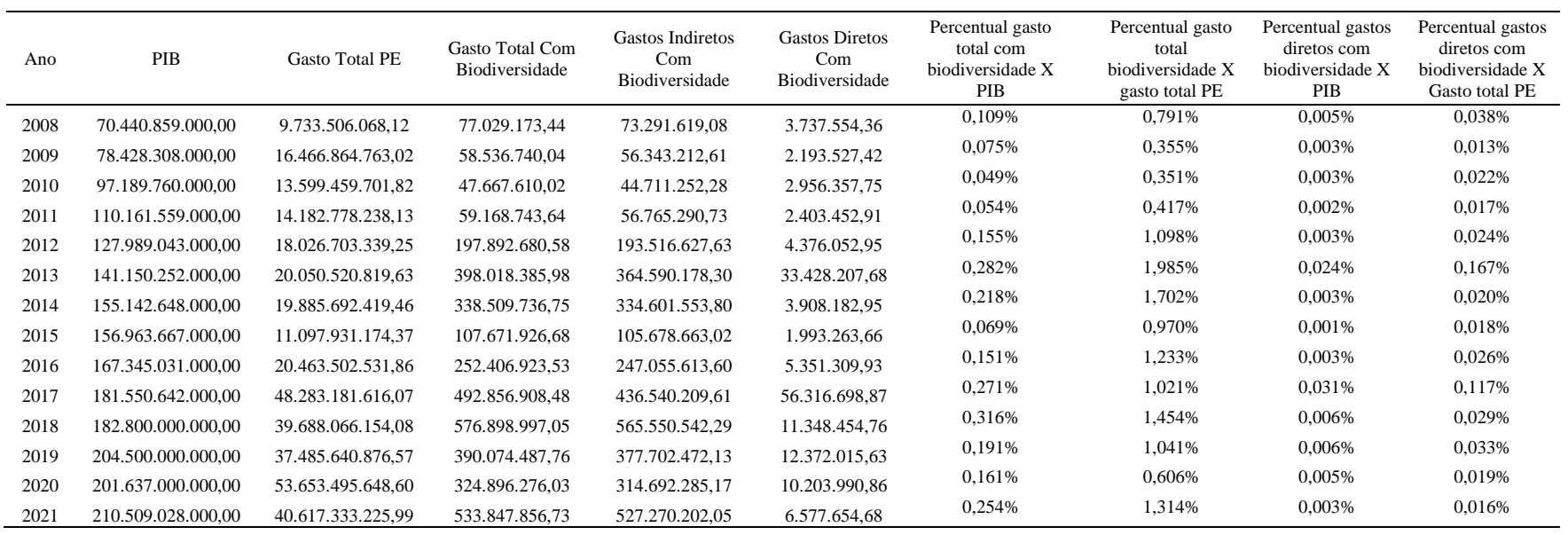

Fonte: Elaborado pelo autor com base nos dados do Portal da Transparência do estado de Pernambuco e deflacionados pelo IPCA para 2021.

O cenário mostrado acima só reforçou o observado em outros trabalhos acerca dos gastos ambientais, em relação a tendência de não priorização desses gastos nos orçamentos. Os estados brasileiros designaram, em média, $0,53 \%$ de seus gastos totais para o meio ambiente (BORINELLI; BACCARO; GUANDALINI, 2017). Os gastos com gestão ambiental no Brasil assumem valores inferiores a $1 \%$ do gasto total. No que tange a relação entre os gastos com gestão ambiental e o PIB nacional, esta não ultrapassou 0,25\% (DANTAS et al., 2014).

Dos países latino-americanos que utilizaram a metodologia BIOFIN para análise de seus orçamentos, foi constatado que dos anos 2000 à 2018, no Brasil, a média dos gastos com biodiversidade em relação ao PIB foi de $0,047 \%$, no mesmo período a média da Colômbia foi de 0,089\%, na Costa Rica entre 2008 e 2013 o valor médio apresentado foi de 0,069\%, em Cuba, analisando os gastos de 2010 à 2016, a média foi de 0,969\% (UNDP, 2018b), no Equador de 2006 à 2015 constatou-se $0,177 \%$ já o México, no mesmo período, apresentou uma média de 0,092\% (UNDP, 2018c).

Relatórios de projetos BIOFIN apontam que, em geral, os gastos em biodiversidade ficam entre $0,03 \%$ e $0,94 \%$ ou entre $0,14 \%$ e $4,60 \%$ em relação ao PIB (UNDP, 2019). Porém, pode-se observar que nenhum dos países latino-americanos apresentou valores acima de $1 \%$ em relação ao PIB. A média de gastos da América Latina e Caribe é cerca de 0,33\%, o que demonstra uma realidade preocupante, visto que os países deveriam ter destinado um valor mínimo equivalente a $0,5 \%$ do PIB anual à gastos com biodiversidade para ter atingido as metas de Aichi até o ano de 2020 (UNDP, 2021).

Ao contrário da interpretação equivocada da maioria, gastos diretos em biodiversidade, com Unidades de Conservação, por exemplo, trazem grande retorno econômico e social contribuindo de forma direta ou indireta com o desenvolvimento do país. A heterogeneidade da gestão ambiental dos estados e municípios ocasionam diversos riscos ambientais coma a falta de fiscalização e regulamentação das atividades, podendo algumas ser nocivas ao meio ambiente. Por isto, vê-se necessário o aumento da alocação de recursos para preservação e conservação (YOUNG; MEDEIROS, 2018). Outro exemplo é o gasto com recuperação ambiental, pode-se afirmar que o gasto necessário para evitar desmatamento em uma área conservada é relativamente menor que o gasto para recuperação de áreas com passivo ambiental, estima-se que com o financiamento de 1 bilhão anual em Pagamento por Serviços Ambientais - PSA, evitaria uma área desmatada de 8,4 milhões de hectares, enquanto o mesmo valor recuperaria apenas uma área de 363 mil hectares de 
floresta (YOUNG et al., 2016). No entanto, muitos tomadores de decisão parecem (explícita ou implicitamente) seguir uma maneira econômica de pensar e se concentrar no impacto econômico de certas decisões, por exemplo, ao competir por investimentos no nível local, ao mesmo tempo em que negligencia o impacto invisível sobre a natureza e o Serviços Ecossistêmicos (HANSJURGENS; KEHL; LOFT, 2016).

Segundo o documento do IBGE que divulgou as "Contas Regionais do Brasil 2002-2017", no Nordeste, seis estados despontaram em crescimento do PIB acima da média do nacional no período 2002-2016. Pernambuco estava entre os seis e cresceu $+2,6 \%$ acima da média nesse período (ETENE, 2019). A causa, foi o crescimento da indústria, refino de petróleo e coque e da fabricação de automóveis, camionetas e utilitários (IBGE, 2019). Atividades essas, potencialmente prejudiciais à biodiversidade. Esse crescimento vem sendo motivado entre inúmeros fatores, por incentivos fiscais dados pelo Governo do estado de Pernambuco (SARABIA, 2018).

De acordo com Dulci (2002), os incentivos fiscais têm por finalidade captar investimentos para determinadas regiões fazendo com que ocorra consequente crescimento econômico das mesmas. São oferecidos benefícios que vão da redução até a isenção de alguns impostos. Em Pernambuco isso é realizado pelo Programa de Desenvolvimento de Pernambuco (PRODEPE), Lei Estadual $\mathrm{n}^{\circ}$ 11.675, de 11 de outubro de 1999, Decreto $\mathrm{n}^{\circ} 21.959$, de 27 de dezembro de 1999. O PRODEPE tem mecanismos de incentivo que acompanham os setores estratégicos de desenvolvimento do Estado. Alguns setores industriais são tidos como prioritários, sendo oferecido um incentivo fiscal maior. Dentre as tipologias de indústrias contempladas com esse benefício está a agroindústria (SARABIA, 2018). No período de 2008 a 2014, foram gastos pelo estado de Pernambuco com incentivos fiscais, cerca de R $\$ 18.8$ bilhões de reais (ADDIPER, 2015).

Podemos traçar um paralelo com o nível federal. Desde o início dos anos 2000, os gastos com subsídios, incentivos financeiros, tributários e créditos eram em sua maioria, destinados ao setor agropecuário/agroindústria (MINISTÉRIO DA ECONOMIA, 2019). Esse setor, é notoriamente conhecido por ser um dos que mais causam perda de biodiversidade no país e no mundo.

A Meta 3, uma das 20 metas do Plano Estratégico 2011-2020 acordada durante a COP 10 no Japão, conhecida como Metas de Aichi, aponta a eliminação de incentivos financeiros nocivos a biodiversidade e a implementação de incentivos positivos. A CDB, ao propor esta meta, acredita que estamos pagando para que a biodiversidade seja destruída, por meio de incentivos lesivos, que favorecem as atividades que destroem a biodiversidade (IUCN; WWF-BRASIL; IPÊ, 2011). No estado de Pernambuco, com o advento da Política Estadual de Pagamento por Serviços Ambientais (PSA) no ano de 2016, podem ser que haja condições para que essas metas estejam cada vez mais perto de ser alcançadas.

\subsection{Gastos com biodiversidade aplicando o fator BIOFIN}

Nessa etapa, com a ponderação dos valores de acordo com o fator BIOFIN, destacou-se na figura 3, durante o recorte temporal estudado, os gastos classificados na Classe 2: Conscientização e conhecimento da biodiversidade tiveram o maior impacto em termos de gastos ponderados representando $27,4 \%$ dos gastos com biodiversidade. Nessa classe, estão os gastos que respondem pela produção de pesquisa e inovação, comunicação, conscientização, educação formal e informal sobre a biodiversidade além da produção de imagens por satélite e levantamento acerca dos recursos naturais para a divulgação e valoração. 
Figura 3 - Gastos públicos com biodiversidade do Governo de Pernambuco de acordo com as classes BIOFIN entre os anos de 2008 e 2021.

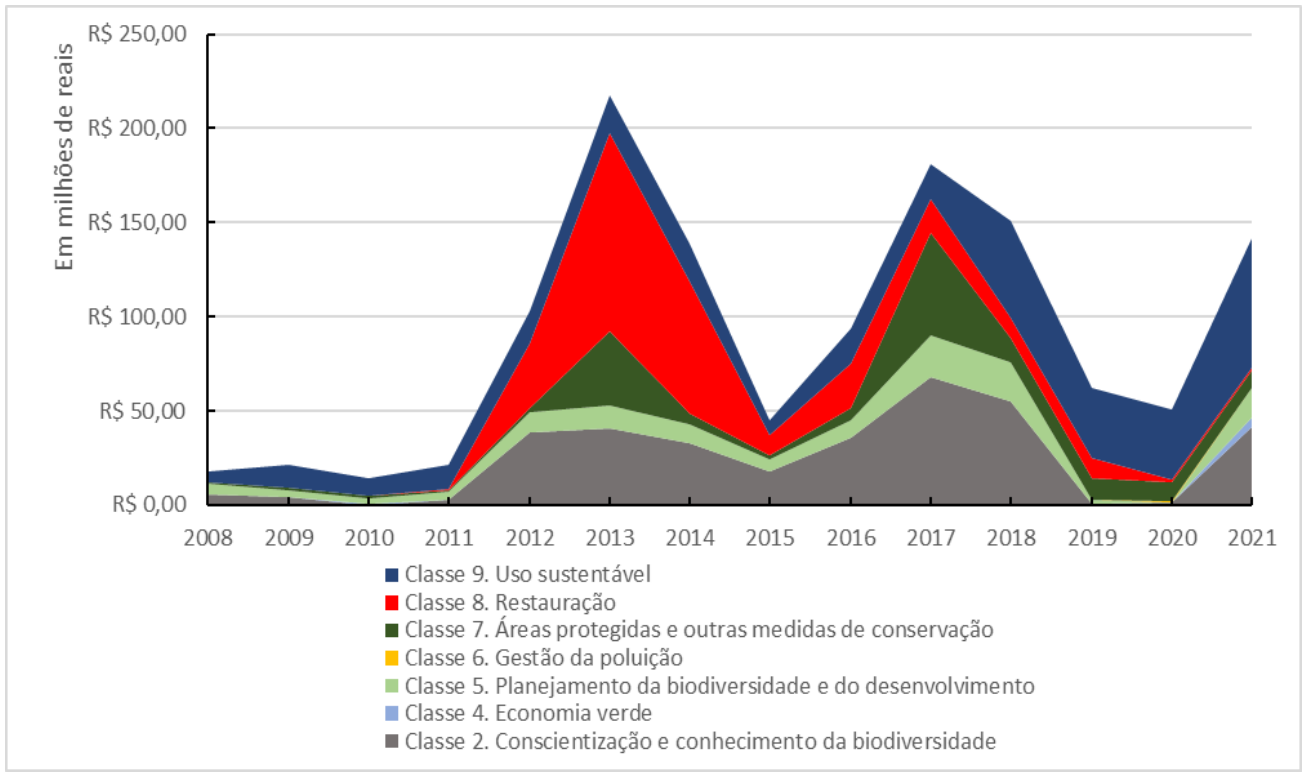

Fonte: Elaborado pelo autor com base nos dados do Portal da Transparência PE, deflacionados pelo IPCA para o ano 2021 e ponderados pelos fatores BIOFIN para cada classe e subclasse.

Respectivamente, a próxima classe com maior gasto acumulado nos anos de avaliação correspondendo a 21,4\%, foi a Classe 9: Uso sustentável. Essa classe corresponde ao uso sustentável de recursos naturais renováveis, conforme definido pela CDB. Evidencia ainda, ações de fomento a administração dos recursos naturais de forma sustentável. Destacam-se nessa classe, as ações de gestão de bacias hidrográficas de forma mais frequente. Possui também iniciativas de agricultura sustentável, agrobiodiversidade e com menor regularidade ações contra a desertificação do solo e gestão dos ecossistemas costeiros. Apesar de envolver muitas ações de vários órgãos do Governo, as subclasses mais presentes, contém fatores de ponderação reduzidos, podendo assim causar efeitos contraproducentes na manutenção da biodiversidade.

A terceira classe com um maior impacto no período de estudo foi a Classe 8: Restauração que respondeu por cerca de $22,7 \%$ de todo o impacto dos gastos em Biodiversidade no período analisado. Nessa classe, aparecem ações de restauração florestal ou a reabilitação de ecossistemas degradados, além de ações de preparação e resposta a desastres. Foram representados nessa classe de forma majoritária, ações de prevenção a desastres com construção de barragens de contenção de enchentes e de forma minoritária, ações de reintrodução de espécies.

As três classes citadas anteriormente corresponderam a $77 \%$ do impacto dos gastos em biodiversidade no estado de Pernambuco nos anos analisados. A quarta classe destacada como o maior gasto no período é a Classe 7: Áreas protegidas e outras medidas de conservação. Classe esta que acumula o maior número de ações que retratam o impacto direto na conservação da biodiversidade. Nela está contida os investimentos em Unidades de Conservação e outros planos que visam a conservação in situ ou ex situ. Todavia, os gastos dessa classe foram na ordem de $12,6 \%$ do total dos gastos totais ponderados. As subclasses mais importantes no que se refere a ponderação BIOFIN são as subclasses 7.1. Gestão das áreas protegidas incluindo áreas de conservação indígenas e comunitárias e 7.2. Extensão das áreas protegidas. De forma predominante, aparecem ações em que são classificadas como gestão de áreas protegidas. Apesar disso, das ações classificadas nessa classe, há somente onze que visam o aumento de áreas protegidas. Dessas, nenhuma houve valor pago. Sinalizando assim, uma estagnação no surgimento de novas Unidades de Conservação no estado de Pernambuco. 
Ocupando o quinto lugar, encontra-se a Classe 5: Planejamento da biodiversidade e do desenvolvimento, atendendo a 9,9\% dos gastos no período. Essa classe, representa sobretudo ações de planejamento, sejam elas políticas, leis ou financeiras, ações de coordenação e fiscalização que abranjam várias categorias de biodiversidade ou questões gerais como biodiversidade, planejamento e políticas de desenvolvimento. No que tange as ações, foram identificados gastos com elaboração de programas e políticas ambientais, gestão de órgãos, apoio a projetos visando a conservação da biodiversidade, melhoria de infraestrutura e equipamentos dos órgãos, além da elaboração de diagnósticos ambientais.

As duas classes que obtiveram o menor nível de impacto dos gastos no decorrer do tempo estudado estão a Classe 4 - Economia verde com 0,5\% e a Classe 6: Gestão da poluição com 0,1\%. Isso é explicado de uma forma bastante simples: os gastos com a classe 6 , se somente deflacionados com o IPCA, correspondem a recursos na ordem de R $\$ 1.1$ bilhão. Porém se ponderados com fator BIOFIN, com a classe 6 tendo os pesos baixos ou até nulos, os valores passam a pouco mais de R\$ 1 milhão. Isso se deve, pois, nessa classe estão os gastos correspondentes a ações de tratamento de esgoto, efluentes e outros tipos de ações que por essência, precisam de uma grande infraestrutura para funcionarem com êxito. A concepção de obras nesse sentido, causam impactos ambientais que compreendem a alteração do ecossistema natural, a modificação da paisagem, o afugentamento da fauna, a remoção da vegetação nativa dentre outros problemas (MELO, 2017). A classe 4 é muito diversa em sua descrição, pode ir desde projetos de engenharia sustentáveis, passando por incentivos financeiros, turismo sustentável até transportes e gestão urbana. Ademais, as subclasses dessas classes têm fator de ponderação BIOFIN que vão de 0 a $25 \%$ configurando relação muito indireta com a biodiversidade justificando assim o baixo valor.

Chama a atenção, a ausência de duas classes: A classe 1: Acesso e compartilhamento de benefícios (ABS) e a Classe 3: Biossegurança. Estas, não foram elencadas em nenhuma ação. A classe 1, tem o foco na autorização previamente informada na distribuição dos benefícios da diversidade genética com foco na igualdade e transparência e em termos acordados de forma recíproca. Essa classe corresponde a ações em que visam promover e reconhecer o conhecimento tradicional como parte ligada a biodiversidade. A importância dessa classe é notada principalmente pela existência de uma Lei Federal que trata sobre Acesso e Compartilhamento dos benefícios da Biodiversidade, a Lei $N^{\circ} 13.123 / 2015$. Porém, embora exista a Lei, nenhuma ação que se referisse a esse tema foi notada na filtragem.

No dia 10 de Julho de 2020, a Câmara dos Deputados aprovou o Projeto de Decreto Legislativo (PDL) 324/2020 que ratifica o Protocolo de Nagoya, elaborado em 2010 na COP 10 e que trata justamente dos recursos genéticos e da repartição dos benefícios da exploração da biodiversidade. O Brasil tinha assinado tal tratado, entretanto faltava a aprovação pela Casa Legislativa. Essa aprovação pode melhorar os investimentos nessa classe no futuro.

Acerca da classe 3: Biossegurança, ela se refere a Prevenção, contenção e erradicação de espécies exóticas invasoras bem como manuseio, transporte e uso seguros de organismos vivos modificados geneticamente que podem ter efeitos adversos na biodiversidade, levando também em consideração os riscos de saúde humana. Como a classe anteriormente referida, nenhuma ação foi verificada nesse sentido.

\subsection{Cenários futuros}

Com relação ao futuro do orçamento Estadual para a biodiversidade, após a obtenção da média móvel identificou-se que a tendência dos valores a serem autorizados é de uma estagnação. A figura 4 indica que a classe 5 , bastante importante para o planejamento das ações ambientais, apontou uma ligeira ascensão nos anos de 2017 e 2018, irá retornar à estabilidade nos anos 
seguintes. A Classe 8, tem uma projeção de estabilidade em valores baixos comparados aos que vinham sido realizados em anos anteriores. A classe 2 depois de uma queda vertiginosa em $2019 \mathrm{em}$ relação a 2018, voltou a crescer em 2021. Por conta disso, tem tendência a ter um crescimento, retornando à estabilidade nos anos posteriores. No que se refere a Classe 7, classe importante para as áreas protegidas, a mesma possui propensão de obter uma leve subida, permanecendo em patamares semelhantes nos períodos seguintes. A Classe 9 após uma grande queda nos valores autorizados em 2019, teve um grande crescimento em 2020. Segundo as projeções, nos anos seguintes, deverá também se manter estável. A estabilidade também ocorre para as Classe 6 e Classe 4 levando em consideração o baixo peso no fator BIOFIN.

Figura 4 - Média móvel dos valores autorizados por classe BIOFIN.

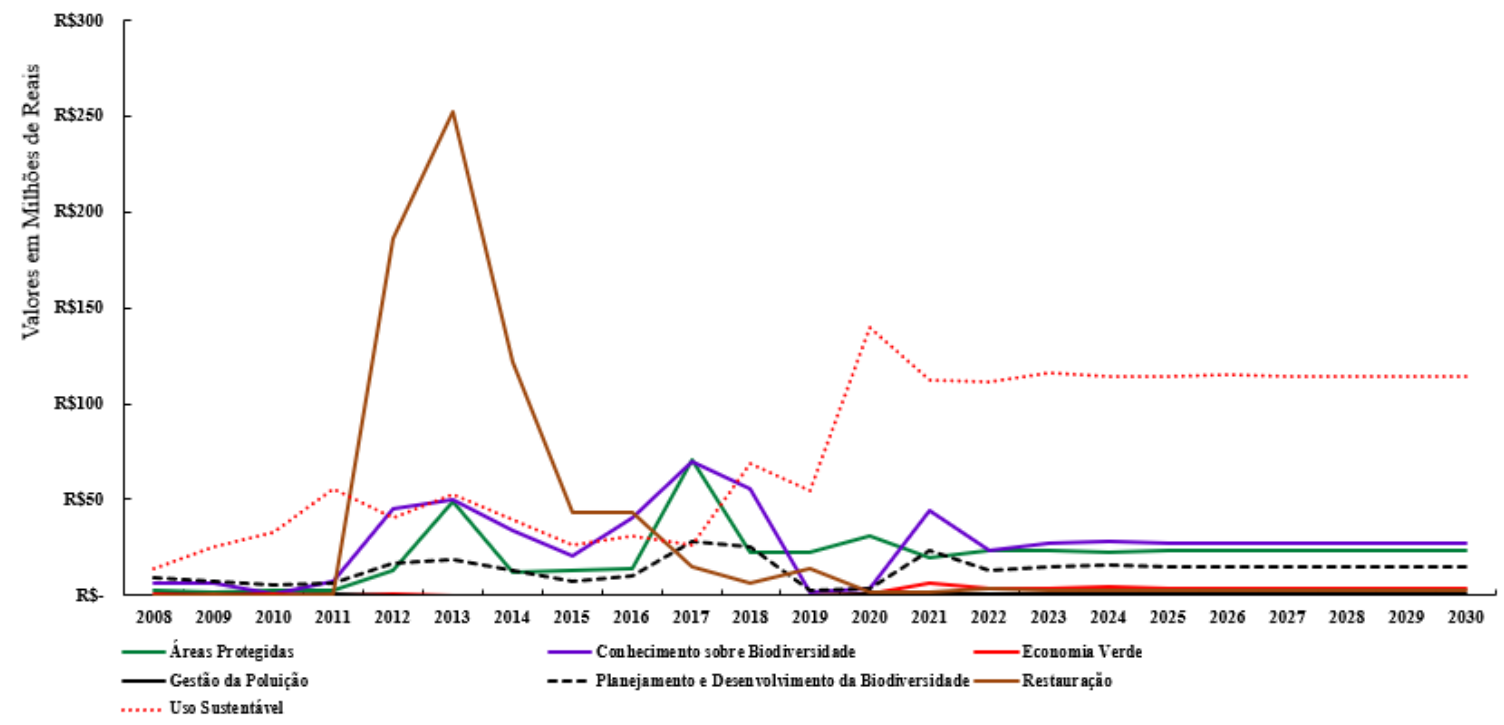

Fonte: Elaborado pelo autor com base nos dados do Portal da Transparência PE, com valores autorizados deflacionados pelo IPCA para o ano 2021 e ponderados pelo fator BIOFIN.

No tocante a um cenário de congelamento dos valores autorizados, a figura 5 mostra que as classes 5 e 2 deverão manter um ligeiro crescimento até 2030. Essas duas classes têm uma relativa importância no que diz respeito aos gastos relacionados a biodiversidade pois ditam ações de criação de políticas públicas que visam a conservação, além da promoção de educação acerca da biodiversidade. A classe 7 , que tem uma importância ainda maior, também terá um crescimento tímido, praticamente beirando a estabilidade, após haver uma queda vertiginosa em 2018 em comparação ao ano anterior. Na classe 8, ocorrem os fenômenos semelhantes localizados na média móvel, ou seja, estabilidade em valores muito baixos. A classe 9, que após uma queda em 2019, voltou a crescer bastante em termos de valores autorizados nos dois anos seguintes. Essa classe terá uma tendência de ligeiro aumento até o ano de 2030. Acerca das classes 6 e 4, foi observada a mesma situação descrita na média móvel.

Figura 5 - Congelamento dos valores autorizados por classe BIOFIN 


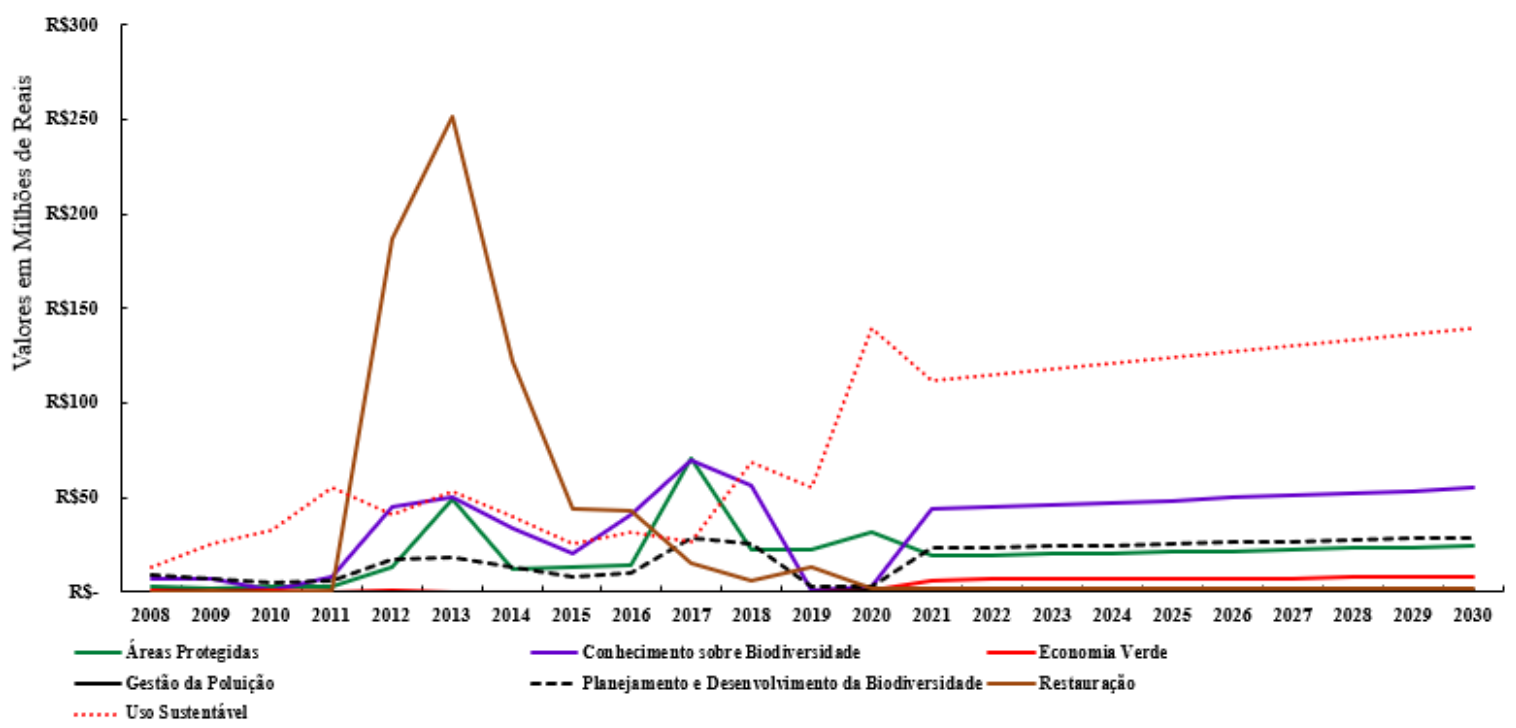

Fonte: Elaborado pelo autor com base nos dados do Portal da Transparência PE, com valores autorizados deflacionados pelo IPCA para o ano 2021 e ponderados pelo fator BIOFIN.

Diante do observado nos cenários podemos incorrer que: nos cenários futuros expostos anteriormente, se levarmos em consideração a média móvel, a situação da alocação e execução de recursos para conservação da biodiversidade terá uma propensão a se manter em estabilidade. Da mesma forma, o cenário onde representa um congelamento de gastos. Porém a situação fica ainda mais crítica para algumas classes e ainda pior se levarmos em consideração a estabilização desses valores em um nível baixo.

Segundo Muanis, Serrão e Geluda (2009), os recursos públicos destinados para a conservação da biodiversidade precisam ser executados de forma contínua, para que assim se almeje êxito nos objetivos de conservação no médio e longo prazo. Inverter os cenários expostos anteriormente garantiriam a conservação da biodiversidade para as gerações atuais e futuras (MALHI et al., 2008) e ainda auxiliaria na manutenção dos recursos naturais e os serviços ecossistêmicos como sequestro de carbono, fontes de água e polinização (WATSON et al., 2014). Esses recursos e serviços são cruciais para o futuro da biodiversidade (PORTILLO-QUINTERO et al., 2015).

A classe 7, que se refere sobretudo a criação e extensão de áreas protegidas, tem uma variação muito grande nos gastos no período avaliado e as tendências futuras não mostram nenhuma evolução que possa causar uma melhora na conservação no estado de Pernambuco. Isso não é exclusivo do estado.

Existe uma necessidade urgente de financiamento para a manutenção de áreas protegidas em todo o mundo (WATSON et al., 2014). As áreas protegidas em todo o mundo têm recebido menos investimentos e países em desenvolvimento geralmente têm menos recursos para manter seus parques e reservas (JAMES et al. 2001, BRUNER et al. 2004, WATSON et al. 2014 apud DE OLIVEIRA; BERNARD, 2017). O custo dos investimentos para manter as UCs é baixo em relação ao ganho de conservação que proporcionam (BALMFORD et al., 2003).

Embora possam parecer alto para alguns, os gastos com biodiversidade e com áreas protegidas configuram-se primordiais e muito menores quando comparados com outras despesas feitas pelos governos (muitas vezes de forma errada), e certamente trazem maiores benefícios a sociedade (MELO et al., 2014). 


\section{CONCLUSÃO}

O desenvolvimento contínuo da sociedade, junto ao impacto das atividades econômicas, certamente trará prejuízos as gerações futuras devido ao alto impacto ambiental causado. Por esse motivo, tornou-se necessário a elaboração de políticas públicas que protejam o meio ambiente. Portanto, as questões ambientais devem ser intrínsecas as pessoas, as empresas e fundamentais para os governos, passando a fazer cada vez mais parte das discussões.

Assim sendo, os estudos que analisam os gastos públicos ambientais e como eles interferem no grau de êxito nas políticas públicas são crescentemente necessários. Isso posto, com base na análise dos dados obtidos e da literatura consultada, se buscou averiguar nesse trabalho como o Governo do estado de Pernambuco aplica os seus recursos com a biodiversidade e se esses recursos estão sendo aplicados de maneira direta a biodiversidade utilizando as metodologias BIOFIN (UNDP, 2018a) e a de Mendes et al. (2017), além de traçar alguns cenários de gastos futuros.

De acordo com a observação dos dados gerados por esse trabalho, foi possível verificar que a execução dos gastos com o objetivo de gerir a biodiversidade no estado de Pernambuco não se mantém de maneira constante. Além disso, foi notado um quadro de subfinanciamento, notado pela baixa participação orçamentária dos gastos com meio ambiente no orçamento total do estado e em relação ao PIB. Os gastos totais em biodiversidade representaram em média 0,168\% do PIB do estado de Pernambuco. Os Gastos diretos com a biodiversidade estão em quadros ainda mais preocupantes com média de $0,007 \%$. Em relação ao orçamento do Estado, os gastos totais em biodiversidade representaram em média $1,024 \%$ e os gastos diretos representaram em média $0,040 \%$.

Além disso foi visto uma grande diferença nos valores autorizados e pagos. Os valores pagos corresponderam em média a $58,1 \%$ dos autorizados. Ou seja, pouco mais da metade dos recursos empenhados são realmente realizados, causando assim prejuízos a realização dos programas e ações do governo que tem por objetivo a conservação e preservação.

Ponderando os valores encontrados por classe BIOFIN, vimos que a Classe 7. Áreas protegidas e outras medidas de conservação só apareceu na quarta posição na ordem das classes que mais apareceram após a classificação das ações. Chama a atenção negativamente, visto que é a classe que acumula o maior número de ações que retratam o impacto direto na conservação da biodiversidade no que diz respeito a criação de áreas protegidas. Os cenários futuros infelizmente não são animadores. Ao que tudo indica, os dados apontam para uma estagnação longínqua.

Apesar do surgimento, de várias legislações no contexto ambiental, os gastos públicos de Pernambuco referentes a biodiversidade encontram-se com uma execução de recursos abaixo do necessário. Quando verificamos os gastos diretos, isso fica ainda mais patente. Por conseguinte, o aumento de recursos a serem executados com biodiversidade faz-se necessário hodiernamente.

Essa deficiência de financiamento além de causar prejuízos a gestão estatal, ainda causa danos aos cidadãos e até a economia do Estado, visto que quando há a má conservação da biodiversidade, serviços ecossistêmicos são prejudicados ou até deixam de ser oferecidos. Assim sendo, os dados aqui mostrados devem subsidiar a relação direta entre a destruição da biodiversidade e perda de serviços ecossistêmicos.

Apesar de destacarmos a importância do trabalho e das informações inéditas aqui apresentadas, o estudo apresenta limitações em três aspectos principais: 1) no aspecto teórico, pelo escassez de estudos dessa natureza, que na sua maioria são relatórios técnicos e não artigos científicos. 2) A própria metodologia Biofin, em especial na definição de suas subclasses e na ponderação da importância delas. Observamos que pode haver sobreposição de temas que se classifiquem em mais de uma classe. Da mesma forma existem classes que aparentemente são sobrevalorizadas, enquanto outra subvalorizadas no que diz respeito a dimensão do impacto 
positivo na conservação da biodiversidade. 3) No aspecto operacional tivemos que nos deparar com superficialidade dos dados do orçamento, que muitas vezes apresentam apenas o título da ação ou programa, sem clareza das reais atividades relacionadas a estas, que permitissem uma classificação de acordo com o Biofin de maneira mais precisa.

Considerando a necessidade contínua de informações sobre gastos públicos ambientais, trabalhos nessa linha temática são importantes para que auxiliem os tomadores de decisão para fazer a execução de recursos de forma coerente, bem como o planejamento de ações futuras no meio ambiental. Podemos destacar nas possibilidades de estudos nessa linha: O aprimoramento da classificação Biofin, para que sejam mais claras em suas definições. Também podemos sugerir uma investigação mais detalhada sobre as atividades realizadas pelas ações orçamentárias, talvez a partir da Lei de Acesso a Informação para obtenção de informações qualitativas. E por fim a realização desse tipo de classificação também em outros estados e em nível municipal para que se tenha um panorama real dos esforços em prol da conservação realizados pelos entes públicos nos três níveis no Brasil.

\section{REFERÊNCIAS}

Agência de Desenvolvimento Econômico de Pernambuco. ADDIPER, 2015. Disponível em <http://www.addiper.pe.gov.br/>. Acessado em 31 jul. 2020.

ARIAS, F. et al. The implementation costs of forest conservation policies in Brazil. Ecological Economics, v. 130, p. 209-220, 2016. DOI: 10.1016/j.ecolecon.2016.07.007.

BALMFORD, A. et al. Global variation in terrestrial conservation costs, conservation benefits, and unmet conservation needs. Proceedings of the National Academy of Sciences of the United States of America, 2003. DOI: 10.1073/pnas.0236945100.

BORINELLI, B.; BACCARO, T. A.; GUANDALINI, N. N. Os gastos ambientais dos estados brasileiros: uma análise exploratória. Revista do Serviço Público, [S. L.], v. 68, n. 4, p. 807-834, out./dez. 2017. DOI:

10.21874/rsp.v68i4.1532. Disponível em: https://revista.enap.gov.br/index.php/RSP/article/view/1532. Acesso em: 2 fev. 2022.

CARDOSO DA SILVA, J.; MARINS, J.; TABARELLI, M. La biodiversidad brasileña, amenazada. Investigación y ciencia, 2002.

CEPAL - COMISIÓN ECONÓMICA PARA AMÉRICA LATINA Y EL CARIBE. Guía metodológica: medición del gasto en protección ambiental del gobierno general. Santiago, Chile: Cepal; Inegi, 2015.

COAD, L. et al. Widespread shortfalls in protected area resourcing undermine efforts to conserve biodiversity. Frontiers in Ecology and the Environment, v. 17, 1 maio 2019. DOI: 10.1002/fee.2042.

COUTO, L. C. do; NETO, J. E. B.; RESENDE, L. L. Flexibilidade do orçamento público perante a execução orçamentária. Revista Mineira de Contabilidade, p. 42-54, 2018. DOI: 10.21714/2446-9114RMC2018v19n1t04.

DANTAS, M. K. et al. Análise dos gastos públicos com gestão ambiental no brasil. Revista de Gestao Social e Ambiental, v. 8, n. 3, p. 52-68, 2014. DOI: 10.24857/rgsa.v8i3.959.

DE OLIVEIRA, A. P. C.; BERNARD, E. The financial needs vs. the realities of in situ conservation: an analysis of federal funding for protected areas in Brazil's Caatinga. Biotropica, v. 49, n. 5, p. 745-752, 2017. DOI: 10.1111/btp. 12456.

DULCI, O. Guerra fiscal, desenvolvimento desigual e relações federativas no brasil. Revista de Sociologia e Política, $\mathrm{n}^{\circ}$ 18: 95-107 Jun. 2002. DOI: 10.1590/S0104-44782002000100007.

DZIBA, L. et al. Summary for policymakers of the global assessment report on biodiversity and ecosystem services of the Intergovernmental Science-Policy Platform on Biodiversity and Ecosystem Services. New York: [s.n.], 2019.

ETENE. PIB de seis Estados do Nordeste cresceram acima da média do País. 19. ed. Fortaleza: Banco do Nordeste, 2019. 2 f. Disponível em: <https://www.bnb.gov.br/documents/1342439/4543398/19_27_03_2019.pdf/93fb57be-74f1- 
0a28-aa16-9273e2c1fab8>. Acesso em: 25 jul. 2020.

FALCO, G. de P. Por que quantificar o meio ambiente?. Revista Vianna Sapiens, v. 1, n. 2, p. $28,2017$.

Forest Monitoring, Land Use \& Deforestation Trends. Global Forest Watch, 2019. Disponível em: <https://www.globalforestwatch.org/>. Acesso em: 3 ago. 2020.

GARSON, S. Planejamento, Orçamento e Gasto com Políticas Públicas: Uma metodologia de apuração para Estados e Municípios. Porto Alegre, RS: Editora FI, 2018.

GRAMKOW, Camila. Política Ambiental no Brasil: perspectivas a partir do gasto público federal. In: OLIVEIRA, Ana Luiza Matos de; DWECK, Esther; ROSSI, Pedro (org.). Economia para poucos: impactos sociais da austeridade e alternativas para o Brasil. 1. Ed. São Paulo: Autonomia Literária, 2018. p. 147-170. Disponível em:

<https://pedrorossi.org/wp-content/uploads/2019/09/Economia-para-Poucos.pdf> Acesso em: 01 fev. 2022.

HANSJURGENS, B.; KEHL, C.; LOFT, L. The economic approach to ecosystem services and biodiversity: Policy design and institutions matter. Gaia, v. 25, n. 3, p. 174-181, 2016. DOI: 10.14512/gaia.25.3.8.

IBGE. Sistema de contas regionais: Brasil 2017. Brasília, 2017.

IUCN; WWF-BRASIL; IPÊ. Metas de Aichi: Situação atual no Brasil. Diálogos sobre Biodiversidade: Construindo a Estratégia Brasileira para 2020, p. 73, 2011.

JAMES, Alexander; GASTON, Kevin J.; BALMFORD, Andrew. Can We Afford to Conserve Biodiversity? Bioscience, [S.L.], v. 51, n. 1, p. 43-52, 01 jan. 2001. DOI: 10.1641/00063568(2001)051[0043:CWATCB]2.0.CO;2.

KAUANO, E.; DA SILVA, J. M.; MICHALSKI, F. Illegal use of natural resources in federal protected areas of the Brazilian Amazon. PeerJ, v. 5, p. e3902, 10 out. 2017. DOI: 10.7717/peerj.3902.

KING, S. et al. Linking biodiversity into national economic accounting. Environmental Science and Policy, v. 116, n. February, p. 20-29, 2021. DOI: 10.1016/j.envsci.2020.10.020.

MALHI, Y. et al. Climate Change, Deforestation, and the Fate of the Amazon. Science, 11 jan. 2008. v. 319, n. 5860, p. 169-172. DOI: 10.1126/science.1146961.

MCLELLAN, R. et al. WWF (ed.). Living Planet Report 2014: species and spaces, people and places. Gland, 2014. 180 p. Disponível em: <https://www.wwf.or.jp/activities/data/WWF_LPR_2014.pdf>. Acesso em: 28 jul. 2020.

MELO, F. P. et al. Football and Biodiversity Conservation: FIFA and Brazil Can Still Hit a Green Goal. Biotropica, 2014. DOI: 10.1111/btp.12114.

MELO, S. Gestão de impactos ambientais na construção civil: Práticas e desafios entre obras de infraestrutura e edificações. VIII Congresso Brasileiro de Gestão Ambiental, p. 1-8, nov. 2017.

MENDES, A. et al. Proposta de abordagem metodológica para avaliação da qualidade do gasto público em mudança do clima. 1a. Edição. Ed.: Banco Mundial. Rio de Janeiro, Brazil. 2017.

MENDES, M. J. Sistema Orçamentário Brasileiro: planejamento, equilíbrio fiscal e qualidade do gasto público. Caderno de Finanças Públicas, n. 9, p. 57-102. Brasília: Esaf, 2009.

MINISTÉRIO DA ECONOMIA, M. E. $3^{\circ}$ Orçamento de Subsídios da União: Relatório de Benefícios Tributários, Financeiros e Creditício no período de 2003 a 2018. Brasília, 2019.

MINISTÉRIO DO PLANEJAMENTO, ORÇAMENTO E GESTÃO. Manual de Elaboração: Plano Plurianual 20082011, Secretaria Planejamento e Investimentos Estratégicos. Brasília, MPOG, 2007.

MOUNTFORD, H.; KEPPLER, J. H. Financing incentives for the protection of biodiversity. Science of the Total Environment, v. 240, n. 1-3, p. 133-144, 1999.

MOURA, A. M. M. DE et al. Gastos ambientais no Brasil: proposta metodológica para aplicação no orçamento federal. Instituto de Pesquisa Econômica Aplicada - IPEA. Brasília, p. 70, 2017. 
MUANIS, M. M.; SERRÃO, M.; GELUDA, L. Quanto custa uma unidade de conservação federal?: uma visão estratégica para o financiamento do sistema nacional de unidades de conservação (Snuc). Rio de Janeiro: Funbio, 2009. 52 p. Disponível em: <https://www.funbio.org.br/wp-content/uploads/2017/07/QUANTO-CUSTA-UMA-UNIDADEDE-CONSERVACAO-FEDERAL.pdf>. Acesso em: 01 mar. 2021.

NASCIMENTO, A. L. da C. P.; FERREIRA, J. D. C.; MOURA, G. J. B. DE. Marsupiais de uma área de caatinga (Pernambuco, Brasil) com registro de nova localidade para Caluromys philander (Linnaeus, 1758). Revista IberoAmericana de Ciências Ambientais, 2013. DOI: 10.6008/ESS2179-6858.2013.001.0008.

PARKER, C. et al. The Little Biodiversity Finance Book. 3rd. ed. Oxford: Global Canopy Programme, 2012.

PORTILLO-QUINTERO, C. et al. The role of tropical dry forests for biodiversity, carbon and water conservation in the neotropics: lessons learned and opportunities for its sustainable management. Regional Environmental Change, 2015. DOI: $10.1007 / \mathrm{s} 10113-014-0689-6$.

OECD. A Comprehensive Overview of Global Biodiversity Finance. Paris: OECD, 2020. 40p.

OECD. Biodiversity: Finance and the Economic and Business Case for Action Annexes to the Report - Executive Summary and Synthesis. n. May, p. 5-6, 2019.

RIBEIRO, C. P. P. Avaliação dos indicadores de desempenho de gastos públicos com o meio ambiente nos estados brasileiros. Revista Mineira de Contabilidade, Belo Horizonte, v. 12, n. 44, p. 35-46, out./dez. 2011.

ROJAS, I. Mecanismos financeiros na CDB: abrindo a porta para mais privatização da biodiversidade. Disponível em: <https://wrm.org.uy/pt/artigos-do-boletim-do-wrm/secao1/mecanismos-financeiros-na-cdb-abrindo-aporta-para-mais-privatizacao-da-biodiversidade/>. Acesso em: 10 fev. 2020.

ROSSI, P; DWECK, E; OLIVEIRA, A. L. M. (org.). Economia para poucos: impactos sociais da austeridade e alternativas para o brasil. São Paulo: Editora Autonomia Literária, 2018. 373 p. Disponível em:

<https://pedrorossi.org/wp-content/uploads/2019/09/Economia-para-Poucos.pdf>. Acesso em: 26 mar. 2021.

SARABIA, Mônica Luize. Investimentos em infraestrutura econômico-produtiva no estado de Pernambuco. Revista Brasileira de Desenvolvimento Regional, Blumenau, v. 6, n. 1, p. 31-56, dez. 2018. DOI: 10.7867/23175443.2018v6n1p31-56.

SCOGNAMIGLIO, H.; BRIGO, L. Programa Open Refine facilita tratamento de dados no jornalismo. Disponível em: <http://reporterunesp.jor.br/2016/12/13/open-refine-dados-no-jornalismo/>. Acesso em: 23 fev. 2020.

SECCHI, L. Políticas públicas: conceitos, esquemas de análise, casos práticos. São Paulo, SP: Cengage Learning, 2010. 149 p.

SEIDL, A. et al. Finance for nature: A global estimate of public biodiversity investments. Ecosystem Services, 2020. v. 46, p. 101216. DOI: 10.1016/j.ecoser.2020.101216.

SILVA, J. M. C. da et al. Funding deficits of protected areas in Brazil. Land Use Policy, v. 100, n. March $2020,2020$. DOI: $10.1016 /$ j.landusepol.2020.104926.

TRIDAPALLI, J. P. et al. Análise Dos Gastos Ambientais no Setor Público Brasileiro: Características e Propostas Alternativas. Revista de Gestão Social e Ambiental, São Paulo (SP), v. 5, n. 2, p. 79-95, 2012. DOI: 10.24857/rgsa.v5i2.340.

UNDP. Análisis de gasto público federal a favor de la biodiversidad en México 2006-2015. Ciudad de México: UNDP, 2018c. 83p.

UNDP. Avaliação dos gastos para a conservação e o uso sustentável da biodiversidade no Brasil - 2012 a 2017 Gastos a partir de fontes orçamentárias. Brasília: UNDP, 2019. 21p.

UNDP. BIOFIN The Biodiversity Finance Initiative Workbook 2018: Finance for Nature. New York: UNDP, 2018a. 192p.

UNDP. Cuba Análisis de los gastos em biodiversidad (AGDB). Havana: UNDP, 2018b. 98p. 
UNDP. Gasto público de Colombia en biodiversidade, 2021. Disponível em:

<https://www.co.undp.org/content/colombia/es/home/-sabias-que-/gasto-publico-de-colombia-en-biodiversidad.html>. Acesso em 2 fev. 2022.

WALDRON, A. et al. Reductions in global biodiversity loss predicted from conservation spending. Nature, v. 551, n. 7680, p. 364-367, 2017. DOI: 10.1038/nature24295.

WALDRON, A. et al. Targeting global conservation funding to limit immediate biodiversity declines. PNAS, v. 110 , n. 29, p. 1-3, 2013. DOI: 10.1073/pnas.1221370110.

WATSON, J. E. M. et al. The performance and potential of protected areas. Nature, 2014. DOI: 10.1038/nature13947.

YOUNG, C. E. F. et al. Estudos e produção de subsídios técnicos para a construção de uma Política Nacional de Pagamento por Serviços Ambientais. Rio de Janeiro: 2016. DOI: 10.13140/RG.2.2.30813.92640.

YOUNG, C. E. F.; MEDEIROS, R. Quanto vale o verde: a importância econômica das Unidades de Conservação brasileiras. Rio de Janeiro: Conservação Internacional, 2018.

YOUNG, C. E. F., RONCISVALLE, C. A. Expenditures, Investment and Financing for Sustainable Development in Brazil. In: CEPAL - SERIE. Medio ambiente y desarrollo. Santiago, Chile, 2002. DOI: 10.13140/RG.2.2.28687.02724.

ANEXO 1 - Classes e Subclasses Biofin e fator de ponderação para classificação dos gastos em biodiversidade.

\begin{tabular}{|c|c|c|}
\hline Classes Biofin & Subclasses Biofin & $\begin{array}{l}\text { Fator de } \\
\text { Ponderação }\end{array}$ \\
\hline \multirow{5}{*}{$\begin{array}{l}\text { Classe } 1 \text { - Acesso e } \\
\text { Compartilhamento de } \\
\text { Benefícios }\end{array}$} & Arranjo Contratual & $50 \%$ \\
\hline & Compensação Financeira & $50 \%$ \\
\hline & Facilitação de acesso a benefícios participativos & $75 \%$ \\
\hline & Protocolo de Nagoya & $100 \%$ \\
\hline & Bioprospecção & $25 \%$ \\
\hline \multirow{10}{*}{$\begin{array}{l}\text { Classe } 2 \text { Conhecimento e } \\
\text { Informação sobre a } \\
\text { biodiversidade }\end{array}$} & Geração de dados e mapeamento espacial & $75 \%$ \\
\hline & Educação formal sobre a biodiversidade & $88 \%$ \\
\hline & Educação informal sobre a biodiversidade & $75 \%$ \\
\hline & $\begin{array}{l}\text { Conscientização à biodiversidade (campanha de sensibilização, educação dos turistas } \\
\text { de parques...) }\end{array}$ & $63 \%$ \\
\hline & Comunicação sobre a biodiversidade & $100 \%$ \\
\hline & Pesquisa cientifica sobre a biodiversidade & $100 \%$ \\
\hline & Inovação tecnológica a favor da biodiversidade & $75 \%$ \\
\hline & Valoração da biodiversidade e dos ecossistemas & $63 \%$ \\
\hline & Conhecimentos locais e indígenas & $100 \%$ \\
\hline & Mecanismo de facilitação da CDB & $100 \%$ \\
\hline \multirow{2}{*}{ Classe 3 Biossegurança } & Organismos geneticamente modificados, incluindo organismos vivos & $100 \%$ \\
\hline & Espécies exóticas invasoras & $100 \%$ \\
\hline \multirow{6}{*}{ Classe 4 Economia Verde } & Responsabilidade social empresarial) & $0 \%$ \\
\hline & Avaliação do impacto ambiental & $25 \%$ \\
\hline & Mitigação dos Gases Estufa (GEE) & $0 \%$ \\
\hline & Cadeia de abastecimento verde & $3 \%$ \\
\hline & Indústrias extrativas sustentáveis & $3 \%$ \\
\hline & Consumo sustentável & $0 \%$ \\
\hline
\end{tabular}




\begin{tabular}{llc} 
& \multicolumn{1}{l}{ Energia sustentável } & $0 \%$ \\
\cline { 2 - 3 } & Investimento sustentável & $0 \%$ \\
\cline { 2 - 3 } & Turismo sustentável & $25 \%$ \\
\cline { 2 - 3 } & Transporte sustentável & $3 \%$ \\
\cline { 2 - 3 } Zonas Urbanas Sustentáveis & $3 \%$ \\
\hline \multirow{3}{*}{$\begin{array}{ll}\text { Classe 5 Planejamento da } \\
\text { Biodiversidade }\end{array}$} & Leis, políticas, e planos relacionados a biodiversidade & $380 \%$ \\
\cline { 2 - 3 } & Outras leis, políticas e planos pertinentes & $75 \%$ \\
\cline { 2 - 3 } & Gestão e coordenação da biodiversidade & $100 \%$ \\
\cline { 2 - 3 } & Financiamento da biodiversidade & $100 \%$ \\
\cline { 2 - 3 } & Avaliação Ambiental Estratégica & $25 \%$ \\
\cline { 2 - 3 } & Planificação Espacial & $100 \%$ \\
\cline { 2 - 3 } & Acordo ambiental multilateral & $75 \%$ \\
\hline
\end{tabular}

\begin{tabular}{|c|c|c|}
\hline \multirow{5}{*}{ Classe 6 Gestão da Poluição } & Proteção do ar e do clima & $0 \%$ \\
\hline & Outras medidas de redução da poluição & $13 \%$ \\
\hline & Gestão de resíduos & $0 \%$ \\
\hline & Manejo de águas residuais & $0 \%$ \\
\hline & Gestão de detritos de poluição costeira e marinha & $13 \%$ \\
\hline
\end{tabular}

Classe 7 Áreas Protegidas e

Outras Medidas de

Caça e comércio da vida silvestre e CITES

Classe 8 Restauração

\begin{tabular}{ll}
\hline Redesenvolvimento e engenharia de sítios & $25 \%$ \\
\hline Gestão de sítios & $25 \%$ \\
\hline
\end{tabular}




\begin{tabular}{|c|c|c|}
\hline & Socorro após desastre & $50 \%$ \\
\hline \multirow{10}{*}{ Classe 9 Uso Sustentável } & Agrobiodiversidade & $100 \%$ \\
\hline & Agricultura Sustentável & $50 \%$ \\
\hline & Aquacultura Sustentável & $28 \%$ \\
\hline & Pesca Sustentável & $53 \%$ \\
\hline & Manejo Florestal Sustentável & $38 \%$ \\
\hline & Gestão Sustentável da terra (UNCCD e usos múltiplos) & $28 \%$ \\
\hline & Gestão marinha e costeira sustentável & $63 \%$ \\
\hline & Pastagens sustentáveis & $28 \%$ \\
\hline & Fauna sustentável & $38 \%$ \\
\hline & Gestão de Bacias Hidrográficas & $25 \%$ \\
\hline
\end{tabular}

